\title{
The Role of Unconscious Awareness of Teachers within Teacher-child Relationship
}

\author{
Elçin Gölbaş ${ }^{1}$, Alev Önder ${ }^{1}$ \\ ${ }^{1}$ Faculty of Education, Department of Early Childhood Education, Marmara University, Turkey \\ Correspondence: Elçin Gölbaşı, Faculty of Education, Department of Early Childhood Education, Marmara University, \\ Turkey.
}

Received: June 11, 2017

Accepted: July 11, 2017 Online Published: July 27, 2017

doi:10.11114/jets.v5i8.2482

URL: https://doi.org/10.11114/jets.v5i8.2482

\begin{abstract}
This article is a descriptive study which aims to investigate preschool teachers' awareness of their own unconscious and the contribution of unconscious processes to educational activities. It presents a literary review on education as a meeting of the teacher and student at a certain point in time and space, not only at a knowledge level but also with their inner psychological processes. The classroom is an arena in which teachers question themselves via interaction, face their true self and unique characteristics. The educational environment can be purified with the search for the teacher's awareness of the unconscious by eliminating ambitions, prejudices and negative psychological experiences. Only then does it transform into an environment of symbolism, higher level thinking and free thinking.
\end{abstract}

Keywords: preschool, unconscious, psychoanalytic

\section{Introduction}

Teachers have two resources in performing their jobs. One is the subject matter to teach, namely the curriculum and the others are psychological aspects like human emotions. The act of teaching can be actualized when these two sources are intertwined inextricably together and are supported with appropriate behavior. To be able to teach effectively, the teacher has to be equipped with classroom management techniques and curriculum knowledge. Those sorts of skills and knowledge are essential to be beneficial to the most special individual of all parents, namely children (Baumlin ve Weaver, 2000). Classroom management techniques include the person being aware of herself and her needs. Teachers who are aware of themselves are also curious about the surrounding world, intellectually active, eager to follow upcoming knowledge, question and update themselves. These characteristics help the teacher to be capable of transmitting her knowledge to the children. According to Price (2002), subject matters in curriculum can only be realized if children's emotions can relate to them. The prerequisite qualities of teachers to accomplish that relationship are some inner psychological processes of the teacher like empathy, unconditional acceptance, compassion, a prejudice-free approach and a self-awareness. When it comes to the teacher's awareness of self, a psychoanalytical approach should also be a useful tool with its fundamental concepts and processes.

Adults can help mitigate difficult experiences and symbolize unknown fear children experience in preshool, since preshool gains the characteristics of a second home. According to Hanifin and Appel (2000), the job of the teacher is to transform unconscious thought into discourse. Teachers can remind children of negative experiences they have had with their parents or authoriy figures unconsciously. Students can react in an exaggerated and angry tone even negative memory does not surface. Price (2006) regards this as resurrection of past experiences in the present instead of an act toward the teacher because the student is attached to the teacher with affection although she can also show anger. The teacher should examine the source of the emotions since emotions are unconscious and can be induced from both the teacher and the student. This study can lead to a more effective education by helping the teacher to understand relationships between them and the child in a deeper and more consistent manner. The teacher should be open to unconscious communication with the student as well as conscious communication. Teachers are much more powerful and knowledgeable than students and are their first experiences of the law and rule of society outside the family. They can also help students communicate their psychological experiences. This is important for the motivation for readiness and low anxiety for learning.

Price (2006) emphasizes that teachers serve as parental and superego figures and can bend the truth while reacting to 
students. This opinion accepts that teachers can have anxiety and inner conflicts instead of being neutral authorities. They exhibit conscious and unconscious attitudes, emotions and behaviours in their relationship with students resulted from their past experiences, conflicts and needs. Good teachers are similar to good therapists. Both teachers and therapists try to regulate the emotional state of the students and patients and they are observer of their own emotional states during teaching/ therapy process. The goal of both teaching and therapy is dialog, relationship and acceptance of the uniqueness of the individual (Paterson \& Groening, 1996). This approach is especially important for preschool children because school is a scary place full of unknown fears from many aspects for very early ages.

\section{Defence Mechanisms in Early Childhood}

Mothers are responsible for infering meaning out of the sensory bombardment following the first days of delivery because they are the first people who can do this before anyone else (Stern, 1985). The baby can not cope with the terror of ignorance of the world while the mother soothes the baby with lullabies, her soft voice, gentle touch and the capacity to stay calm against the baby's unrest. This is the way of transmitting the mother's resilience and the capacity to self-soothe her child. Good care gives the baby the experience of being held in the mind and being understood. This experience constructs the basis of thinking capacity. Mental representations of a good mother help children to be more resilient and resistant to hardships. These children can mitigate helplessness through mental representations. Lack of representations leave children defenseless in the face of anxiety. If children are raised by careless, indifferent and merciless mothers, they believe that they are not valuable and they have nothing to offer other people. They realise that the void is at a deeper level than they can imagine and no one can fill this void while they continuously search for someone else's power which they can not find within themselves. Defense mechanisms provide protection from these feelings. Youell (2015) asserts that defense mechanisms hinder learning but render strength to fight against anxiety. These children do not seem to be interested in the learning process (they can regularly forget their books, materials, even answers). This obliviousness might reflect their feelings of being useless, unnecessary, and someone to forget (exact feelings in the presence of their mother). This feeling is transferred to the teacher unconsciously. The teacher might receive this reflection unconsciously and regard herself as unnecessary and void to teach nothing. One of the best indicators of trauma is memory loss of the student (Tieman, 2013). To understand the process of internalizing knowledge, the teacher should understand the deep inner feelings of students (fears for example), mental power and how they react to disappointments (Mayes, 2009).

The resistance to learning in adolescents symbolizes separation from the Oedipal mother psychoanalytically. Parental wishes and antipathy of the students coming from negative environments are frequently reflected on teachers (Mayes, 2002). One of the coping mechanisms to fight against destructiveness of students is split mechanism. The mechanism is based on dividing good and bad strictly and trying to avoid merging of good and bad. Splitting mechanism works by dissociating bipolar feelings as far as possible at school. One of the teachers is idealized and extolled while the other is sacrificed and discredited. The beloved teacher is responsible for all the goodness while the hated teacher is responsible for all the bad. Teachers are generally under the spell of idealization and they unconsciously nurture this narcissism by encouraging discrimination. This same mechanism may work by idealizing mother or father at home. The school is not different in this sense. Adults should emphasize that both mother and father (all teachers) have good parts (Youell, 2015).

Another problem of relationships is the distribution of power (Mayes, 2012). If children are extremely exposed to interfering mothers, they can not experience being authentic and they perceive teachers' interventions as penetration into their personality. They may regard helpful and approaching behaviour of the teacher as threatening to their self. Even if the teacher can approach, acceptance of what the teacher has given requires acceptance of inability, ignorance and despair. The student transfers this feeling instead of living existential fear and coping with the darkness of this fear (Mayes, 2012). The ability of feeling thankful requires gratitude and digestion for what the teacher has offered (like accepting the mother's milk). Aggressive students struggle with envy (like the child not accepting the mother's milk) toward the teacher because of her superiority and knowledge (Klein, 2014). Acceptance of ignorance brings with it the feeling of how empty the self is before the learning process. New information is against the omnipotent feelings and an attack on our ignorance.

There is a parallelism between learning capacity and self development (Youell, 2015). Loss of time and mortality reminds us of other loss like weaning. A child's resilience and coping mechanism depends on how difficult the first loss is. Struggling against the feeling of dependency is the student's task, not the teacher's. Children have been observed punishing themselves in the face of separation from the teacher because they get stuck on the idea of being abandoned by loved ones whom she does not dare to blame (Price, 2006). Having difficulty at the transition between themes, finishing homework at the last minutes, experiencing classroom change as a traumatic event are all denial of the fear of loss of time and the reality of mortality. The arrival of a new student to the classroom, announcing the end of the course, or vacation plans are reminiscence of a previous loss (Youell, 2015). Seperation brings anxiety like: "Is the teacher happy with my parting? Does she love me? Could I leave a mark on her? Did she see us as her children? Was I special for her? Are her new students hardworking? Will we be on good terms with my new teacher? Will we be able to like each other? Do I find it difficult establishing rapport with my new teacher? Did we hurt our old teacher?" For the teacher: "Will they adopt their 
new teacher? Will they like her? Could I leave a mark on them? Will I establish a rapport with my new class?

Tieman (2013) has been a participant observer at Francis W.Parker School at Chicago. He was teaching with a fake identity. In a course he could not shut the children up and desperately put his head between his hands and prayed "Lord, you trusted me with these children who are Your most sacred creatures, give me the passion to stay in this classroom. A student heard his prayer, got anxious, and told his friends to be quiet: "Class, be quiet, otherwise he will abandon us just like the previous teachers. Most of the students of this class live with single parent (mother) and some of them do not even have a mother or a father. $7^{\text {th }}$ grade children have changed 7 English teachers and just one of them could stay for all day long. The only stable male figure in children's life is Tieman. He observed that children do not know how to cope with separation anxiety and the right manners asking for the teacher's attention. Tieman himself was abandoned by his father at the age of 10. He realized that he wanted to leave children just like his own father and hurt them the same way. However he did not leave the children with an awareness and interrogation of his unconscious.

\section{The Psychological Processes of the Teacher}

Matthews (2007) mentions about an educator whom Anna Freud gave a consultation. This educator cared for 3 children and the second of these children had difficulty in learning. The educator gave all her energy to this child. The child overcame learning difficulties through time and started to get interested in his environment. This development caused the child's parents to get more compassionate with the child. Actually the parents had been neglecting this child for the sake of the other children. The moment of the child's most successful performance was very interesting. The educator felt that she was fed up with the child although she deeply loved him. She abandoned the child and changed her destination for a new teaching position. Years passed and she analyzed her teaching experience through psychoanalysis. The educator realized that she identified with this child. She gave the child the attention and the care that she had craved for and could not reach for years. The parents' support destroyed the initial identification and the success of the child caused an envy in the educator because she had never achieved this much. Since the educator could only tolerate the failure of the child, providing too much love and compassion, it ended with envy and the rage of the educator towards the child. The best alternative was abandoning the child when painfully faced with her deficiencies. At this point this question inavitably arises: Would the educator have abandoned the child if she could have controlled her hate towards him. The teachers' attention catches the children and they neglect (abandon) children for different reasons. The teacher's unawareness of her inner psychological processes may lead children to be confronted with some negative behaviors from the teacher like neglecting, intimidating and belittling the child...

Winnicott (Matthews, 2007) took in a 6 year old juvenile delinquent to his home and tried to prevent him from escaping. $\mathrm{He}$ analyzed his intense hate and rage toward the child who also ran away from his home and was later found in the police station. Winnicott says "I never hit this child. What if I had hit him, I would have then faced the limits of my anger. I had to differentiate my emotions toward him: hate originated in me and was then passed on to him. Winnicott attributes the success of the teaching on her ability to differentiate her emotions and not forcing the child to pay for her own emotions.

Aggressive students may sometimes trigger a defensive reaction from a teacher (Tieman, 2013) because teachers have a tendency to avoid adverse situations and negative feelings. They can feel guilty toward a specific student or blame students for their own feelings. So they can feel distant and dissociated from children. One of the ways a teacher finds a resolution is based on emotions and is the acceptance of results or feelings. Without an analysis and description of this unconscious process, teachers can abuse children with power struggles. Teachers' negative expectations about the student's achievement can transform to a self-fulfilling prophecy. It results in disliking the student, undervaluing her and focusing on her faults. This vicious cycle directs students into making more mistakes (Paterson ve Groening, 1996). Teachers may be indifferent, hostile and unfair. They may be prone to punishing or devaluing students. The central agenda of the classroom is invisible to the conscious mind but it is apparent through our behaviour. The emotional world of the teacher has a great effect on students and teaching awareness (Shim, 2012). Unconscious and unresolved prejudices are reflected on students and reveal the dynamics of the teacher's relationship with authority (Price, 2006). According to Mayes (2009), a student who is frequently beaten by her father may have difficulty in learning about middle age tortures or the treatment of slaves in history class. In this case, the teacher may perceive the student as a lazy person who is reluctant to do her homework. However, the resistance of the student is much more painful and complex. The content and the subject of the lesson is just a tool, not a goal. Teachers who try to develop a multidimensional perspective for their students comprehend that identity structure of the student is not an external factor. It is contrary to an important part of the educational environment. The emotional and cognitive development of the child are so intertwined that it is impossible for one to develop without the other. Emotional handicaps can cause learning disability while success in the classroom brings emotional well-being concomitantly. Actually there is no superficial division between emotional and cognitive. Learning is an inseparable process with psychological and interactive structures. 


\section{Unconscious Processes in Teacher-child Relationship}

Robertson emphasizes a similar approach. He proposes (1999:159-160) several unconscious processes within teacher-student relationship:

- Student's positive (admiration) or negative (hate) overreactions or neutral position (indifference, disregarding, ignoring),

- Overreaction to a specific student, sudden impairment of a relationship with a student, distant and hostile behaviours,

- Defensive behaviours (withdrawing support or ignoring the student),

- Aggressive comunication between the teacher and the student,

- Emotional distance of the student or oversensitivity for a student's absence,

- Teacher's decentralization of her own authority, treating students as equal, or a parental figure (mother or father) or a child figure,

- Transfering to traditional gender roles while behaving in a non-sexist manner,

- Preserving boundaries although removing the barriers toward a specific student,

- Student's intolerence to criticism, perceiving criticism as an attack to her personality or oversensitivity to a specific student's criticism,

- Unexplained learning difficulties (writing, mathematics, communication or thinking),

- Too much need for approval of the teacher and vice versa,

- Fear of a teacher or fear of a student,

- To feel an obligation to "save" a student or quite the contrary student's feeling of an obligation to save a teacher,

- Student's envy for or competition with the teacher or a teacher's envy of or competition with a student.

Tieman observed (2013) that denial, displacement (especially if the target person is unavailable directing emotions toward a different target), rationalisation, reaction formation, isolation, regression, repression and sublimation are defence mechanisms used in educational environments. If parents impose their own desire excessively on children, this causes children to be ambivalent about what they want. Indecisive children experience "self" only in relation with someone and associate this person with hate and idealization by making this person as the source of reality and identity. The person she idealizes is sometimes her teacher, trainer, and the boss (Mayes, 2012).

\section{Methods of Analyzing Unconscious}

Teachers can adopt an accepting attitude by the insight they gain from interrogation of the unconscious. They can accept and preserve the borders of emotions, thoughts and behaviors independently of what they smybolize. If the approach of the teacher induces negative emotions in the student, the teacher may choose a very different approach or direct the student to a different teacher. Teachers may have vulnerabilities. They should be aware of how these vulnerabilities reflect on their behavior. The main agenda is not the teacher or the student, it should be the relationship and the damages in the relationship between them (Tieman, 2013). The teacher can examine her own anger and guilt at a supervision with a reliable school counselor or psychologist. A reflective teacher who can think about her emotions and the relationship between herself and her students can transform the emotions into symbols and make use of her mind to serve for the mental health of the students (Sahin, 2012). Acceptance of the emotions of the students and differentiation of the emotions (belong to whom) can be studied by school counselors and the supervision frame can be internalized to determine the correct borders of the relationship (Robertson, 1999).

Self- integrated, unified, consistent and individualized personalities are found effective to fight against the emotional imbalance of the student. Based on unconscious dynamics and psychoanalytical terminology (Robertson, 1999) in student teacher relationships, Hayes (2004) adopted the composition of therapist- patient relationship into the teacher student relationship. In this analogy, we can reflect the role of school psychologist to the teacher in order to build a safe classroom environment at a micro level. The emotions of the therapist (or the teacher) may be approaching (emotional satisfaction, mercy, identification with the student or the patient), avoiding (getting bored, not understanding, not discovering the material the patient or the student brings), negative emotions (sadness, anger, anxiety). The therapist (namely the teacher) can ask herself why she behaves differently toward a specific patient (or student) for example giving too much advise. The she ensures her atypical behavior: "I felt too much responsibility for the patient (student)". "I felt that I should be more directive". The therapist (the teacher) should search for the similarities between her patient (student) and the significant 
people in her life (Hayes, 2004). So the teacher stops thinking like "This student is always late, I need to change it" and reaches the awareness of "Why is this student communicating with me in this manner? What is happening between us?" (Tieman, 2013).

The school should develop a loving, working (learning) and playing capacity in mentally healthy individuals. So it can be discussed that it is important to let the student develop her own potential. The teacher can also focus on the process by showing students that it is composed of love and the essence of learning is based on the teacher's encapsulating of the student. Tieman (2013) adopted Winnicott's famous saying "there is no baby without a mother, we can not imagine a baby independent of a mother" (Kohut; 2004: 258) into education by an analogy "these is no student, when there is no teacher, namely the teacher's thinking and symbolizing capacity, the power of transforming trauma into a digestable form, there is no student". The most important difference between active learning and rote memory is attributing emotions to the learned subject and constructing an emotional tie with the subject (Youell, 2015). Learning is a passionate occupation that the individual attaches emotionally to the subject (Mayes, 2009). The teacher should consider psychological dynamics for all students instead of just children with learning disabilities or emotional hardships. When teachers are faced emotionally with their anxieties, fears by school counselor or a psychologist, they will be ready to face students'fears and anxieties (Şahin, 2011). The teacher will simulate the healthy and encapsulating relationship with the school counselor or psychologist and bring it into the classroom. Parallel processes recreate the relationship between the teacher and the student within the frame of "here and now" (Scanlon ve Weir, 1997).

Tieman (2013) asserts that self is experienced in the relationship with the other who reflects the individual. As a parental figure, the teacher can support emotional development by creating the loving and caring environment which a healthy mother enables. The teacher can ask for psychological support to create this environment. Supervision defines the reality of existence of someone. This makes learning, development and self acceptance possible. Pack (2012) argues that an effort which denies the reality of the self conduce dilemmas that hinder learning.

Mayes (2009) emphasizes the importance of giving attention to psychological processes as well as learning and teaching activities. When the teachers are endowed with a sufficient psychological education, even experiencing psychoanalysis, they not only transmit knowledge but provide corrective experiences in which children get an emotional benefit of the knowledge. The teachers should be psychoanalytically informed even though they are not therapists to guide students in the curriculum, communication with each other and relating to themselves. So unhealthy repression mechanism are prevented and psychic energy is directed to the more constructive and socially acceptable actions. One of the difficulties in the lives of children is to balance between drive satisfaction and drive control. A psychologically healthy and psychoanalytically informed teacher can help students to balance between greedy id and harsh superego. Ignoring unconscious just prevents creativity. To be authentic existentially the teacher should consider students as emotional and ethical beings in all their psychodynamic complexity. The teachers should be individuals who shape their students' identity, free, empower and make them happier.

\section{Discussion}

Britzman, (2014), focuses on the silence and deeper meaning of teacher and student behaviours. It indicates the essential executive psychological mechanisms in them. She states that (1998) teacher's unconscious and behaviours have a cost for the student. Britzman (2009) bases this view on the unconscious of the student in which she regards the teacher as an omnipotent person. Their psyche meet at the unspoken area of the desires, expectations, disappointmens and power struggles. The teacher can educate herself for bearing uncertainty and intense affect of the students (Diamond, 2014). Macdonald (2014) proposes that emotional absence of the therapist can be persecutory for the patient. The same idea can be proposed for the teachers: Negative attitudes, comments or emotional absence of the teacher can be persecutory for the student because existence of the students in the classroom is validated by the teachers as their first self-actualization is accepted by their parents.

\section{Conclusion}

The importance of analysis of the unconscious of teachers is discussed by Britzman $(1996,2013)$ in Canada. However it only includes high school and college instructors in meetings which they share their own cases. These cases were very rich in the sense that political and private life transferences were held. Tieman (2013) held meetings in a primary school. He dealt with transferences of parental roles instead of political and private life issues.

The main purpose of this article is to take these perspectives into consideration for preschool teachers in gaining awareness and reflect this awareness into their relationship with their students. Then the student-teacher relationship and the learning environment is based on more solid foundations and gets healthier. Epecially preschool children who have separated from their families for the first time and are entering the world of the unknown. Then this perspective becomes more important for the psychological health of children. When I considered early childhood education, it seems to me there are not enough studies in the subject of teachers' and children's unconscious. Because of this there is a need for a 
multidisciplinary study in Turkey of education and psychology. This study will lead a focus group of teachers and a part of the doctoral thesis of "Teacher student interaction at preschool: The role of unconscious in creating an emotionally holding preschool classroom: transferential response of teachers" at Marmara University.

\section{Acknowledgements}

I am deeply grateful to Robert Wildermoth and Murat Özüdoğru for correction of the language of the article.

\section{References}

Baumlin, J. S., \& Weaver, M. E. (2000). Teaching, classroom authority, and the psychology of transference. Journal of General Education, 49(2), 75-87. https://doi.org/10.1353/jge.2000.0011

Britzman, D. (1998). Lost Subjects, Contested Objects: Toward a Psychoanalytic Inquiry of Learning. Albany: State University of New York Press.

Britzman, D. (2009). The poetics of supervision: a psychoanalytical experiment for teacher education. Changing English: Studies in Culture \& Education, 16(4), 385-396. https://doi.org/10.1080/13586840903391948

Britzman, D. (2013). Between psychoanalysis and pedagogy: Scenes of rapprochement and alienation. Curriculum Inquiry, 43(1), 95-117. https://doi.org/10.1111/curi.12007

Britzman, D. (2014). That other scene of pedagogy: a psychoanalytic narrative. Changing English: Studies in Culture and Education, 21(2), 122-130. https://doi.org/10.1080/1358684X.2014.897038

Britzman, D., \& Pitt, A. J. (1996). Pedagogy and transference: Casting the past of learning into the presence of teaching. Theory into Practice, 35(2), 117. https://doi.org/10.1080/00405849609543711

Diamond, M. J. (2014). Analytic mind use and interpsychic communication: Driving force in analytic technique, pathway to unconscious mental life. The Psychoanalytic Quarterly, 83(3), 525-563. https://doi.org/10.1002/j.2167-4086.2014.00106.x

Hanifin, E., \& Appel, S. (2000). Transference and psychological-mindedness in teachers. Australian Journal of Teacher Education, 25(2). https://doi.org/10.14221/ajte.2000v25n2.3

Hayes, J. A. (2004). The inner world of the psychotherapist: a program of research on countertransference. Psychotherapy Research, 14(1), 21-36. https://doi.org/10.1093/ptr/kph002

Klein, M. (2014). Haset ve Şükran. Metis Yayınları: İstanbul.

Kohut, H. (2004). Psikanalizin “Öteki” Yüzü. İthaki Yayınları.

Macdonald, J. (2014). "Formal" feedback in psychotherapy as psychoanalytic technique. Psychodynamic Practice. 20(2), 154-163. https://doi.org/10.1080/14753634.2013.771566

Matthews, S. (2007). Some notes on hate in teaching. Psychoanalysis, Culture \& Society, 12(2), 185-192. https://doi.org/10.1057/palgrave.pcs.2100125

Mayes, C. (2002). Personal and archetypal transference and counter-transference in the classroom. Encounter, 15(1), 34-49.

Mayes, C. (2009). The psychoanalytic view of teaching and learning. J. Curriculum Studies, 41(4), 539-567. https://doi.org/10.1080/00220270802056674

Mayes, C. (2012). Psychodynamics of teaching and learning. Encounter: Education for Meaning and Social Justice, 25(3), 57-67.

Min, S. J. (2012). Exploring how teachers' emotions interact with intercultural texts: A psychoanalytic perspective. Curriculum Inquiry, 42(4), 472-496. https://doi.org/10.1111/j.1467-873X.2012.00606.x

Pack, M. (2012). Two sides to every story: A phenomenological exploration of the meanings of clinical supervision from supervisee and supervisor perspectives. Journal of Social work Practice, 26(2). https://doi.org/10.1080/02650533.2011.611302

Paterson, B., \& Groening, M. (1996). Teacher induced countertransference in clinical teaching. Journal of Advanced Nursing, 23, 1121-1126. https://doi.org/10.1046/j.1365-2648.1996.01377.x

Price, H. (2002). The emotional context of classroom learning: a psychoanalytic perspective. European Journal of Psychotherapy, Counselling \& Health, 5(3), 305-316. https://doi.org/10.1080/1364253031000091381

Price, H. (2006). Jumping on shadows: Catching the unconscious in the classroom. Journal of Social Work Practice, 20(2), 145-161. https://doi.org/10.1080/02650530600776830 
Robertson, D. L. (1999). Unconscious displacements in college teacher and student relationships: Conceptualizing, identifying, and managing transference. Innovative Higher Education, 23(3). https://doi.org/10.1023/A:1022990316742

Şahin, A. (2011). Psikanalitik pedagoji tarihine kısa bir bakış (A brief historical overview of psychoanalytic pedagogy) Psikanaliz Yazıları 22. Bağlam Yayınları: İstanbul.

Şahin, A. (2012). Teacher's countertransference reconsidered. In:Bainbridge, A.\&West, L. (Ed.), Minding a gap. (pp.103-116). Karnac books: London.

Scanlon, C., \& Weir, W. S. (1997). Learning from practice? Mental health nurses' perceptions and experiences of clinical supervision. Journal of Advanced Nursing, 26, 295-303. https://doi.org/10.1046/j.1365-2648.1997.1997026295.x

Stern, D. N. (1985). The Interpersonal World of the Infant: A View from Psychoanalysis and Developmental Psychology. New York: Basic Books.

Tieman, J. S. (2013). Miss Freud returns to the classroom. Schools: Studies in Education, 10(1), 91-110. https://doi.org/10.1086/670002

Youell, B. (2015). Öğrenme İlişkileri. Bağlam Yayınları: İstanbul.

\section{Copyrights}

Copyright for this article is retained by the author(s), with first publication rights granted to the journal.

This is an open-access article distributed under the terms and conditions of the Creative Commons Attribution license which permits unrestricted use, distribution, and reproduction in any medium, provided the original work is properly cited. 